\title{
La-Ni based Alloys Preparation for Hydrogen Reversible Sorption and their Application for Renewable Energy Storage
}

\author{
Artem Chesalkin $^{1 *}$, Petr Moldrik ${ }^{2}$, Alexandr Martaus ${ }^{3}$ \\ 1 ENET Centre - Research Centre of Energy Units for Utilization of Non Traditional Energy Sources, VSB- \\ TUO Technical University of Ostrava, Ostrava, Czech Republic; artem.chesalkin@vsb.cz \\ 2 ENET Centre - Research Centre of Energy Units for Utilization of Non Traditional Energy Sources, VSB- \\ TUO Technical University of Ostrava, Ostrava, Czech Republic; petr.moldrik@vsb.cz \\ 3 CET-Centre for Environmental Technology, VSB-TUO Technical University of Ostrava, Ostrava, Czech \\ Republic; alexandr.martaus@vsb.cz \\ * Correspondence: chez47@gmail.com ; artem.chesalkin@vsb.cz Tel.: +420-774-269-863
}

\begin{abstract}
Metal hydrides are one of the types of functional materials that allow safe and compact storage of a large amount of hydrogen, which is increasingly used today as an alternate fuel or energy source. The possibility of obtaining the initial energy necessary for the production of hydrogen by electrolysis process from renewable energy sources, such as solar panels and wind generators, makes hydrogen energetic quite attractive and rapidly developing industry sector. Solid form of hydrogen storage with the possibility of reversible sorption, gives opportunity for creation autonomous energy storage systems. La-Ni based alloys allow hydrogen storing at ambient temperatures and pressure not higher than $15 \mathrm{bar}$, which makes the application of these alloys quite practical, interesting and prospects for analysis and modifications on the ways of stored hydrogen capacity increasing, alloys price reducing and application for renewable energy storage.
\end{abstract}

Keywords: metal hydrides; hydrogen storage; La-Ni based alloys; alloy modification and analysis; renewable energy storage

\section{Introduction}

The study of hydrogen sorption and desorption processes is of interest for various fundamental and practical problems. In the field of hydrogen energy, it is necessary to study hydrogen storage materials [1]. Hydrogen accumulators are investigated for maximum storage capacity [2], the conditions for the introduction and withdrawal of hydrogen and the number of such cycles are studied [3]. In nuclear power engineering and in those industries where such hydride-forming materials as zirconium alloys [4], various grades of steel [5], titanium alloys [6] are subjected to hydrogenation

The most important energetic process is the combustion of hydrogen, which is accompanied by the release of large amounts of energy and water without any harmful emissions. Among all the kinds of fuel, hydrogen has the highest gravimetric calorific value $120 \mathrm{MJ} / \mathrm{kg}=33.33 \mathrm{kWh} / \mathrm{kg}$ which is higher than many of liquid hydrocarbons $\sim 45 \mathrm{MJ} / \mathrm{kg}[7,8]$.

One of the best metal for hydrogen storage is palladium $(\mathrm{Pd})$ and its alloys, but the price of this material does not allow its use widely $[9,10]$. Complex hydrides have a biggest storage hydrogen density in comparison with other types of hydrides, but most of them are not relevant for reversible hydrogen sorption. The micro-porous adsorbents and interstitial hydrides have similar hydrogen capacity, but intermetallic hydrides can operate at ambient temperatures. The aim of hydrogen storage technologies is to reduce the volume that hydrogen naturally occupies in its thermodynamically stable state under ambient conditions. Different ways of hydrogen storage are shown in Figure 1. 


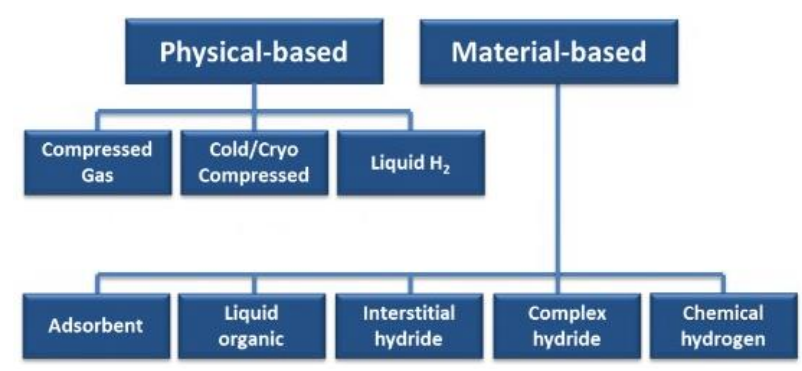

Figure 1. Different ways of hydrogen storage [11,12]

Most of metal hydrides formed by direct reaction with gaseous hydrogen, the thermodynamics of metal-hydrogen formation can be found in the literature [13, 15-19]. Because the La-Ni based metal hydride formation reaction requires rearrangement of metal atoms while in the hydride reaction the motion of atoms is minimal, the hydride formation goes at low temperature [14].

Analysis of scientific works in the field of $\mathrm{LaNis}$ based alloys production and modification shows the existing problems on the way of widespread using these materials for hydrogen storage.

In the works of A. Apostolov, L. Bozukov, N. Stanev, P.Tcholackov devoted to hydrogen absorption in mishmetal-nickel-chromium-iron intermetallic compounds and hydrogen absorption in $\mathrm{MmNi}$ type pseudo-binaries compounds, done by team of researchers from company «LabTech Int. Ltd.» Sofia and from personal working experience with ( $\mathrm{LaCe}) \mathrm{Ni} 5$ based storage system HBond1500, made also by LabTech company, few problematic aspects of alloy practical using were determined. First of all, it is a problematic of full system charging or complete hydrogen sorption in (LaCe)Nis alloy. Completeness of hydrogen sorption depends on the accurate thermoregulation of ongoing hydride formation process. In addition, maximal hydrogen weight capacity of unmodified $\mathrm{LaNi}_{5}$ and $(\mathrm{LaCe}) \mathrm{Ni}_{5}$ alloys is not more than $1.8 \% \mathrm{wt}$. The second problematic aspect is a complexity of alloys producing. This issue has become a significant obstacle for the project realization. The classic method of alloy production is a direct fusion from the pure bulk metals in the oven.

The same method is used by «LabTech» company. Alloys synthesis, by carrying out joint chemical and heat treatment transformations and using metal oxides and chlorides, instead of bulk metals, is not typical and common method of production. In this regard, lack of equipment for the synthesis of LaNis based alloys was appeared. To perform the alloys synthesis, the new system was assembled. Quartz or graphite crucible with reagents and covered by cap should be placed to the oven. The crucible lid has two holes for gas pipes connection. One end of the tube is connected to a source of inert gas cylinder with argon. The second tube is used for gas byproducts removal from the reaction zone. Further analysis of the practical works of other authors shows that the chemical method of $\mathrm{LaNi}$ alloy production from metal oxides and chlorides is applicable in practice. In the work of G.Giresan, S.R. Sankaranarayanan, L.J. Berchman was described an example of LaNis alloy production by thermo-chemical synthesis and using magnesium $(\mathrm{Mg})$ as a reducing agent: $\mathrm{La}_{2} \mathrm{O}_{3}$ $+10 \mathrm{Ni}+3 \mathrm{Mg} \rightarrow 2 \mathrm{LaNi}+3 \mathrm{MgO}[20]$.

Moreover, in the work of S. Kamasaki, Y. Misaki, T.Kanayama, M.Yamada method of alloy modification by additional metal powders of $\mathrm{Co}$ and $\mathrm{Al}$ for alloy lifetime increasing during operation was described [21].

\section{La-Ni based alloys application in Laboratory of Hydrogen Technologies in TCO}

For the private sector and small production areas the pressure of hydrogen production and storage should not be very high for safety and regulation reasons. Working pressure in metal hydride storage tanks could not be more than 1.0 -1.5 MPa. Low storage pressure with big amount of stored hydrogen together with the small physical volume of storage vessels provides a big advantage for hydride systems application.

Private houses and industrial facilities, which identify independent from any vendor and external energy sources, always attracted people in the whole world. The main task is an integration of all presented technologies into a single power system adapted for home and industrial applications. Solar and wind power systems and autonomous backup power supply as well as fuel 
cells are widely used in industry, vehicles, etc. and also used for household needs. There are also ready-made solutions for the integration of photovoltaic power systems and hydrogen technologies. Such hybrid power systems were also examined and tested by the authors in other studies [22 -24]. Experimental independent stand-alone energetic system with implemented hydrogen technologies was developed and realized in Laboratory of Hydrogen Technologies at VSB-Technical University of Ostrava [25], located at the Technology Centre of Ostrava (TCO), established within the project ENET - Energy Units for Utilization of Non-traditional Energy Sources. This project focuses on both the practical implementation of means designed for processing and utilisation of alternative fuels for energy production as well as to enhance their conversions into electric power and heat as well as the supporting electric power technologies, designed mainly for storage of electric power either from the distribution grid or from the internal production facilities at TCO. Figure 2 shows the block diagram describing the layout of this system at TCO and basic view of hydrogen part of the TCO.

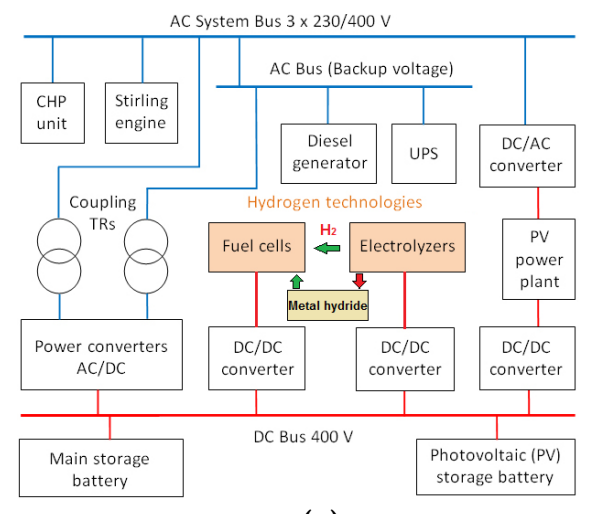

(a)

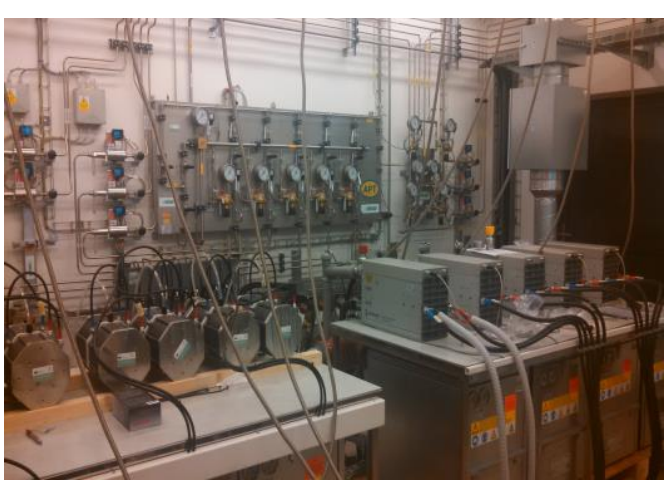

(b)

Figure2. (a) The block diagram of the power system in TCO, (b) basic view of hydrogen part of the TCO

The TCO is fitted with the following primary power sources: The co-generation (CHP) unit with an asynchronous generator with the power output of $105 \mathrm{~kW}$ and the heat output of $135 \mathrm{~kW}$; the micro co-generation unit with a Stirling engine delivering $2 \mathrm{~kW}$ of electric power and $10 \mathrm{~kW}$ of heat (both units can operate both with natural gas and pyrolysis gas, obtained through thermal cracking within a steam cracker); the photovoltaic power plant with the installed capacity of $22.5 \mathrm{kWp}$, formed by both polycrystalline panels partially fitted on trackers, together with amorphous panels made of roof foil. Primary consumption of the power produced by all the sources mentioned above takes place inside the TCO. Any potential surplus is then supplied to the local distribution grid. The topology of power grid in this TCO is based on the main AC Bus rated $3 \times 230 / 400 \mathrm{~V}$.

The TCO further has the battery room formed by the main and auxiliary battery blocks. The first block is made of lead traction batteries with the total capacity of $930 \mathrm{Ah}$. The second block is formed by LiFePO batteries with the total capacity of $200 \mathrm{Ah}$. The primary purpose of this block is to ensure a link to the photovoltaic power plant and to adjust the fluctuation of power consumption among electrolysis (hydrogen generation). The main storage bloc (lead batteries) allows for storage of approximately $550 \mathrm{kWh}$ of electric power. The auxiliary storage block (LiFePO battery) then holds further $80 \mathrm{kWh}$ of electric power. Semi-conductor power converters are linked to coupling transformers in order to ensure a connection between the DC Bus and both AC Buses. Their management enables modification of their functioning into various operating modes for transfer of electric power or its active filtration. These converters ensure two-way transfer of electric power with respect to the power distribution grid rated $50 \mathrm{~Hz}$ at the connection point. They may also ensure power supply to a designated local power grid in an off-grid mode, to cater for potential disconnection of TCO from the power distribution grid.

The hydrogen technologies subject to our research are included within the electric power storage system of TCO. These are based on the closed hydrogen cycle principle, where the electric power supplied from the photovoltaic power plant is transformed into chemical energy of hydrogen gas via electrolysis of water using AEM (Anion-Exchange Membrane) type electrolyzers. The hydrogen is 
then stored in the gas - compressed form and in the solid form by forming metal hydrides in La-Ni based alloys and re-used to generate electric power using low-temperature fuel cells of PEM (Proton exchange membrane) type. The hydrogen storage system installed comprises eight electrolyzers with the total electric input of $17 \mathrm{~kW}$ and the total hydrogen production capacity of $4 \mathrm{~m}^{3} / \mathrm{h}$. Basic parameters of one AES500 electrolyzer are shown in Table 1. The hydrogen storage system further includes five modules of hydrogen fuel cells with the total electric output of $40 \mathrm{~kW}$. These are used for reverse conversion of the hydrogen gas into electric power and heat energy. Measured operation characteristics of this electrolyzer are shown in Figure 3.

Table 1. Basic parameters of electrolyzer [26]

\begin{tabular}{cc}
\hline Chracteristic & Value \\
\hline Cell number & 38 (2 blocks x 19 cells) \\
Maximum $\mathrm{H}_{2}$ production & $504 \mathrm{Nl} / \mathrm{h}$ \\
Operating current & $30 \mathrm{~A}$ \\
Operating voltage & $34.6-35.5 \mathrm{~V}$ (each block) \\
Power consumption & $2075-2132 \mathrm{~W}$ \\
Efficiency & $85 \%$ \\
\hline
\end{tabular}

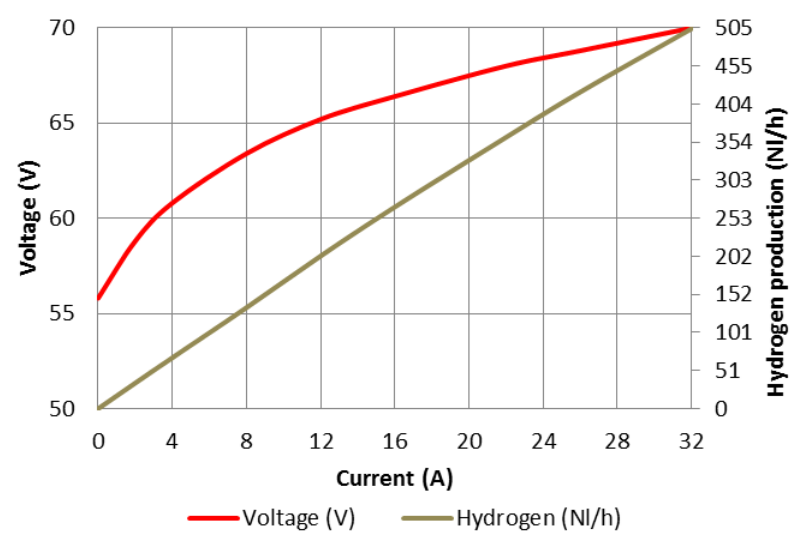

Figure3. Basic characteristics of electrolyzer

The daytime operation with the photovoltaic plant in full pace delivering sufficient power involves operation of electrolyzers producing hydrogen gas that is collected into high-capacity pressure vessels and in metal hydrides storage system. Any fluctuations of electric power delivered by the photovoltaic power plant (due to the proportion of cloud-covered skies) are balanced using the LiFePO batteries. This feature then ensures reliable operation of electrolyzers. The electric power produced by fuel cells is primarily used by the TCO on its own; any potential surplus can be then supplied into the power distribution grid.

\section{La-Ni based alloys preparation}

\section{Materials and Methods}

Mixing of the initial components was conducted under inert atmosphere in glow-box to prevent oxidation and saturation of air moisture. 
Reagents weights for samples preparation of La-Ni based alloys from metal chlorides are shown in Table 4, from pure powder metals are shown in Table 5. In practice, synthesis was performed for obtain 5-10 g of each of the La-Ni based alloy samples.

La-Ni based alloys were prepared in reaction chamber of induction furnace, shown in Figure 4. Table 3 described the main working characteristics of the furnace.

Table 3. The main working parameters of the furnace used for alloys preparation [27]

\begin{tabular}{lccc}
\hline Furnace type & T $\max ,{ }^{\circ} \mathbf{C}$ & Working volume, $\mathbf{1}$ & Power nom., kW \\
\hline LAC VP20/17 & 1700 & 20 & 7 \\
\hline & &
\end{tabular}

Figure 4. General view of induction furnace used for alloys preparation

\subsection{La-Ni bsed alloys preparation from metal chlorides}

Crucibles with different samples were placed to the reaction zone of the induction furnace:

- Sample (A) - $\mathrm{LaNi}$ prepared at $750^{\circ} \mathrm{C}$, holding time 80 minutes

- Sample (B) - LaNis prepared at $900{ }^{\circ} \mathrm{C}$, holding time 80 minutes

- $\quad$ Sample (C) - LaNis prepared at $900{ }^{\circ} \mathrm{C}$ holding time 90 minutes

Temperature program of alloy synthesis:

- $\quad$ Step 1: heating up to $750-900{ }^{\circ} \mathrm{C}$ during 80 minutes

- $\quad$ Step 2: 750-900 ${ }^{\circ} \mathrm{C}$ temperature holding during 80-90 minutes

- $\quad$ Step 3: cooling till $200{ }^{\circ} \mathrm{C}$

Step 1-3 should be carried out at inert atmosphere to prevent alloy oxidation and saturation by air moisture

- $\quad$ Step 4: transfer of alloy samples to a desiccator for subsequent analysis

All temperature profiles of the samples synthesis and their comparison diagram are shown in Figure 5.

Table 4. Reagents calculation for alloy preparation from metal chlorides

\begin{tabular}{cccc}
\hline Reagent & $\mathbf{L a N i}_{5}, \mathbf{g}$ & $\mathbf{( L a C e )} \mathbf{N i}_{5}, \mathbf{g}$ & $\mathbf{( \mathbf { L a M m } ) \mathbf { N i } _ { 5 } , \mathbf { g }}$ \\
\hline $\mathrm{LaCl}_{3}$ & 566,55 & 429,20 & 431,66 \\
$\mathrm{CeCl}_{3}$ & & 431,34 & \\
$\mathrm{NiCl}_{2}$ & 1496,42 & 1133,65 & 1140,13 \\
$\mathrm{Mm}$ & & & 241,30 \\
$\mathrm{LiH}$ & 238,44 & 222,60 & 181,90 \\
\hline
\end{tabular}



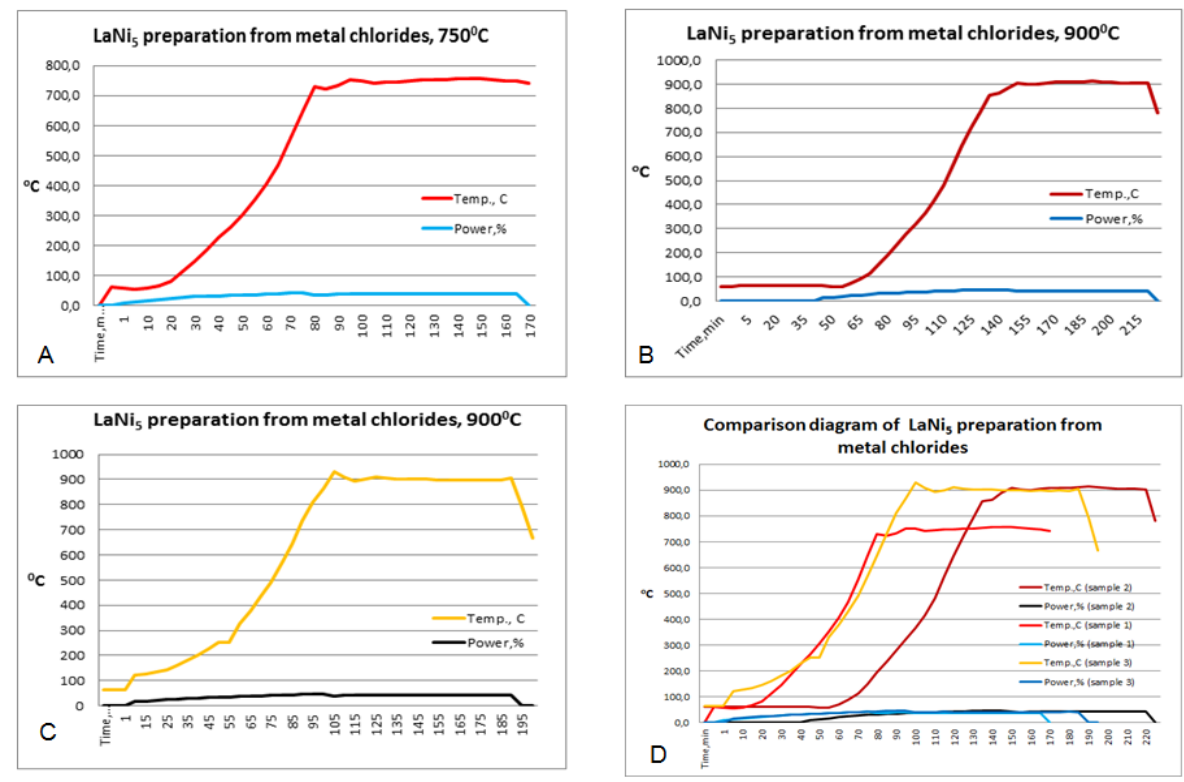

Figure 5. Temperature profile of alloys preparation in induction oven from metal chlorides

\subsection{La-Ni bsed alloys preparation from pure powder metals}

Crucibles with samples were placed to the reaction zone of the induction furnace:

- $\quad$ Sample (A) - LaNis; Sample (B) - (LaCe)Nis; Sample (C) - (LaMm)Nis

Temperature program of alloy synthesis:

- $\quad$ Step 1: heating up to $1500^{\circ} \mathrm{C}$ during 90 minutes

- $\quad$ Step 2: $1500{ }^{\circ} \mathrm{C}$ temperature holding during 180 minutes

- Step 3: cooling till $200^{\circ} \mathrm{C}$

Step 1-3 should be carried out at inert atmosphere to prevent alloy oxidation and saturation by air moisture

- Step 4: transfer of alloy samples to a desiccator for subsequent analysis

Temperature profile of the samples synthesis is shown in Figure 6.

Table 5. Reagents calculation for alloy preparation from pure metals

\begin{tabular}{cccc}
\hline Reagent & $\mathbf{L a N i}_{5}, \mathbf{g}$ & $\mathbf{( \mathbf { L a C e } _ { \mathbf { N i } } \mathbf { 5 } _ { 5 } , \mathbf { g }}$ & $\mathbf{( \mathbf { L a M m } ) \mathbf { N i } _ { 5 } , \mathbf { g }}$ \\
\hline $\mathrm{La}$ & 320,86 & 243,07 & 244,46 \\
$\mathrm{Ce}$ & & 245,19 & \\
$\mathrm{Ni}$ & 677,87 & 513,54 & 516,47 \\
$\mathrm{Mm}$ & & & 241,30 \\
\hline
\end{tabular}

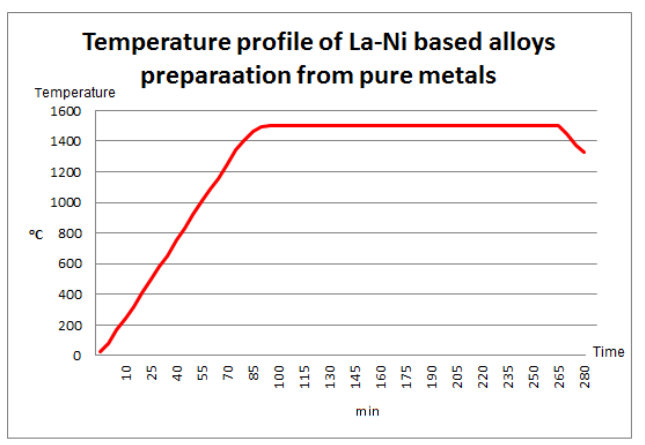

Figure 6. Temperature profile of alloys preparation in induction oven from pure powder metals 
Data about chemical composition and structure of prepared alloys were obtained from XRD analysis of relevant samples. Measured samples were evaluated using appropriate software and compared with ICCD database. Measured sample was not stable under the ambient conditions. From this reason sample was gently grinded under flow of nitrogen and covered with $6 \mu \mathrm{m}$ thick Mylar foil to eliminate exhibition of air humidity. Process of sample scanning is shown in Figure 7. Broad diffraction at positions 16.0, 19.3 and 30.0 2 theta corresponds to the Mylar foil.

XRD measurement conditions: diffractometer Rigaku SmartLab; goniometer geometry - BraggBrentano theta-2theta; lamp - CoK $\alpha\left(\lambda_{1}=0.178892 \mathrm{~nm}, \lambda_{2}=0.179278 \mathrm{~nm}\right)$; detector - D/teX Ultra 250; range of the measurement $-5-90^{\circ}$ 2theta; sample holder - glass holder with cavity depth $0.5 \mathrm{~mm}$.

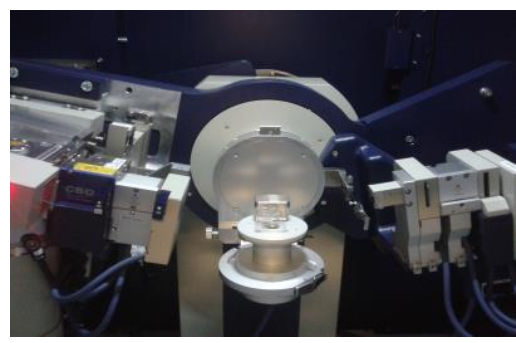

Figure 7. XRD analysis of the samples: La-Ni based alloy sample under X-ray scanning

Unfortunately the XRD analysis results were not sufficiently clear and informative to determine the composition of the alloys, because of similar nature and as a consequence of the identity of peaks of rare-earth components used for the preparation of alloys. This situation was however solved with the aid of the electronic microscopy analysis use.

\subsection{SEM analysis of La-Ni bsed alloys}

The scanning electron microscope Quanta FEG 450 (FEI) with EDS microprobe analysis OCTANE (EDAX) was used for characterization of the morphology of the studied samples. Images were taken by use of secondary electrons and backscattered electron detectors at $15-20 \mathrm{kV}$. Microprobe analysis was performed with an EDAX detector and processed with the EDAX software, shown below in Figure 8.

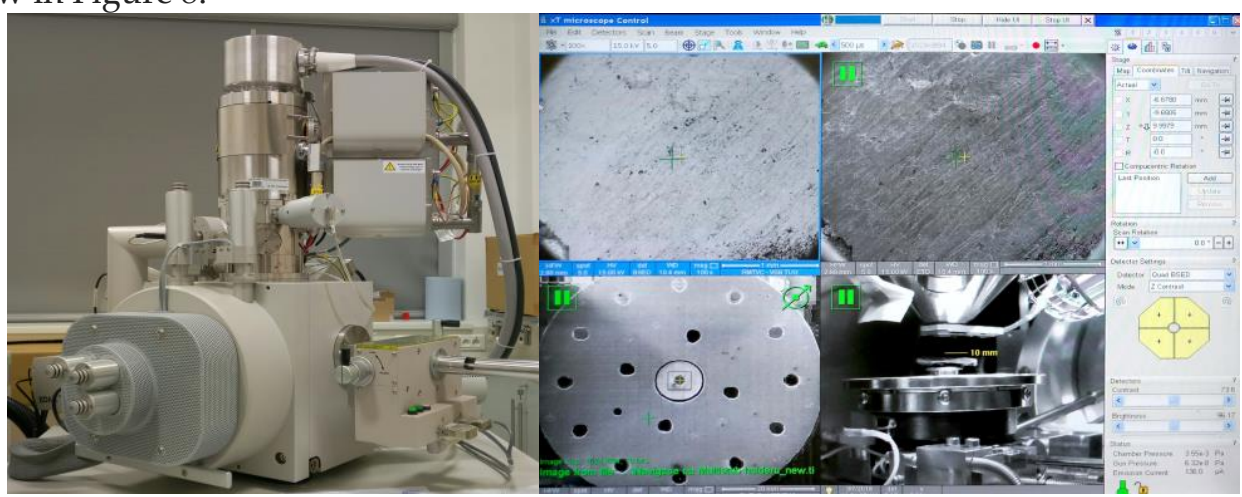

(a)

(b)

Figure 8. The basic view during analysis (a) scanning electron microscope (b) SEM analysis software

\section{Results of prepared La-Ni based alloys analysis}

\subsection{Analysis results of La-Ni bsed alloys prepared from metal cholrides}

\subsubsection{LaNis alloy analysis results}

The results of electron microscopy gave good information about alloys composition, distribution of phases and alloy homogeneity. Tables 6,7 show composition of the LaNi5 sample, prepared at $1100^{\circ} \mathrm{C}$. Figures 9,10 show the SEM analysis images and spectrum of the prepared alloy. 
Table 6. Sample $\mathrm{LaNi} 5$ prepared at $1100{ }^{\circ} \mathrm{C}$ (La-Ni-O composition).

\begin{tabular}{cccccc}
\hline Element & $\mathbf{W t}, \mathbf{\%}$ & $\mathbf{A t}, \mathbf{\%}$ & $\mathbf{Z}$ & $\mathbf{A}$ & $\mathbf{F}$ \\
\hline $\mathrm{O}$ & 9,51 & 39,66 & 1,2538 & 0,3364 & 1,0002 \\
$\mathrm{Cl}$ & 3,30 & 6,21 & 1,1731 & 0,6545 & 1,0114 \\
$\mathrm{La}$ & 72,26 & 34,69 & 0,9146 & 1,0174 & 1,0047 \\
$\mathrm{Ni}$ & 13,06 & 14,83 & 1,1204 & 0,8991 & 1,0000 \\
Total & 100,00 & 100,00 & & & \\
\hline
\end{tabular}

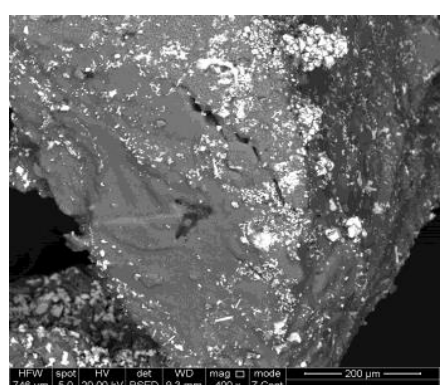

(a)

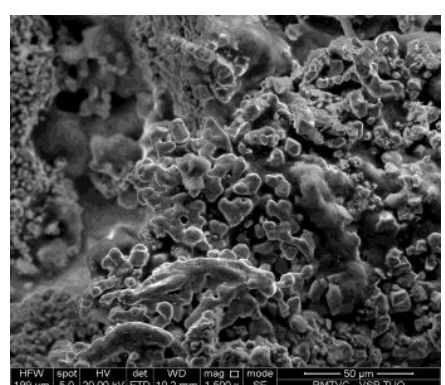

(b)

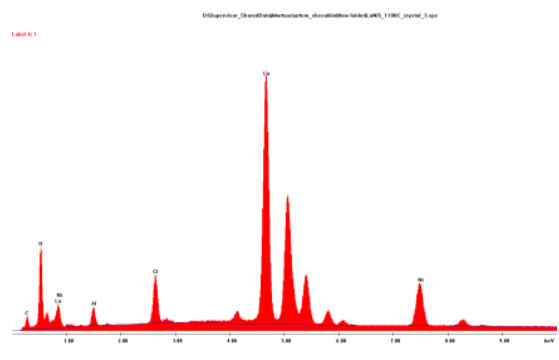

(c)

Figure 9. LaNis sample prepared at $1100^{\circ} \mathrm{C}$ : (a) sample view at $400 \times$ zoom SEM analysis ; (b) sample view at $1500 \times$ zoom SEM analysis ; (c) SEM spectrum

Table 7. Sample LaNis prepared at $1100{ }^{\circ} \mathrm{C}$ (Ni crystal).

\begin{tabular}{cccccc}
\hline Element & $\mathbf{W t}, \mathbf{\%}$ & $\mathbf{A t}, \mathbf{\%}$ & $\mathbf{Z}$ & $\mathbf{A}$ & $\mathbf{F}$ \\
\hline $\mathrm{O}$ & 3,17 & 10,66 & 1,1376 & 0,3362 & 1,0039 \\
$\mathrm{Cl}$ & 1,18 & 1,79 & 1,0452 & 0,6990 & 1,0043 \\
$\mathrm{Ni}$ & 96,65 & 87,55 & 0,9934 & 1,0002 & 1,0000 \\
Total & 100,00 & 100,00 & & & \\
\hline
\end{tabular}

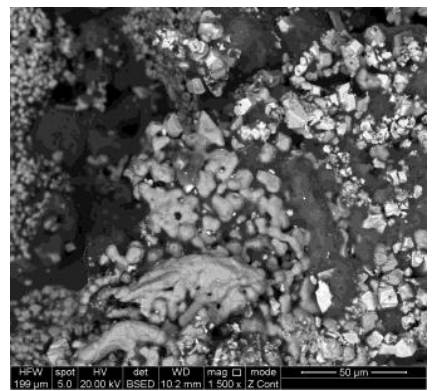

(a)

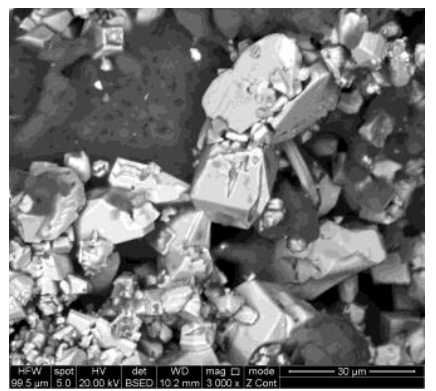

(b)

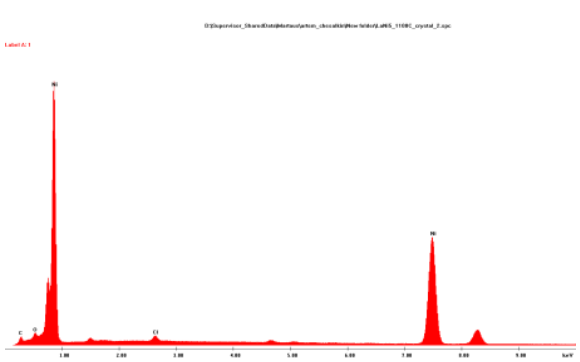

(c)

Figure 10. LaNi5 sample prepared at $1100{ }^{\circ} \mathrm{C}$ : (a) sample view at $1500 \mathrm{x}$ zoom SEM analysis ; (b) sample view at $3000 \times$ zoom SEM analysis ; (c) SEM spectrum

\subsection{2. (LaCe) Nis alloy analysis results}

Tables 8,9 show composition of the (LaCe)Nis sample, prepared at $900^{\circ} \mathrm{C}$. Figures 11,12 show the SEM analysis images and spectrum of the prepared alloy.

Table 8. Sample ( $\mathrm{LaCe}) \mathrm{Ni}$ prepared at $900{ }^{\circ} \mathrm{C}$ (La-Ce-O composition).

\begin{tabular}{cccccc}
\hline Element & $\mathbf{W t}, \boldsymbol{\%}$ & $\mathbf{A t}, \boldsymbol{\%}$ & $\mathbf{Z}$ & $\mathbf{A}$ & $\mathbf{F}$ \\
\hline $\mathrm{O}$ & 25,79 & 63,67 & 1,1872 & 0,4125 & 1,0003 \\
$\mathrm{Cl}$ & 0,56 & 0,62 & 1,1018 & 0,6892 & 1,0103 \\
\hline
\end{tabular}




\begin{tabular}{cccccc} 
La & 27,66 & 7,87 & 0,8626 & 1,0374 & 1,0002 \\
$\mathrm{Ce}$ & 36,58 & 10,31 & 0,8687 & 1,0421 & 1,0003 \\
$\mathrm{Ni}$ & 0,56 & 0,38 & 1,0525 & 0,9109 & 1,0002 \\
other & 8,85 & 17,15 & & & \\
Total & 100,00 & 100,00 & & & \\
\hline
\end{tabular}

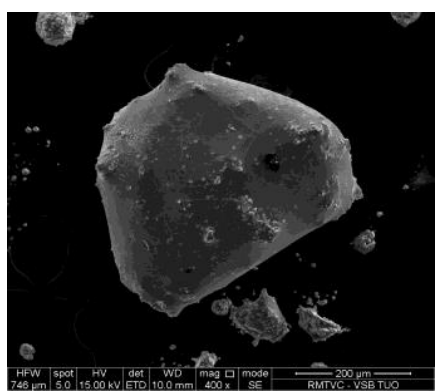

(a)

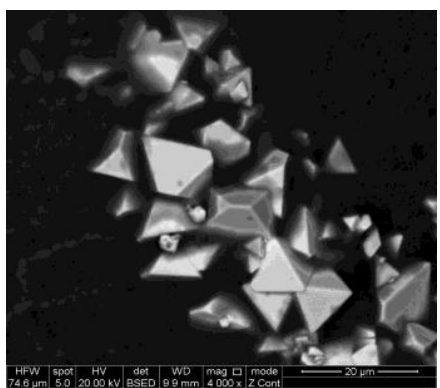

(b)

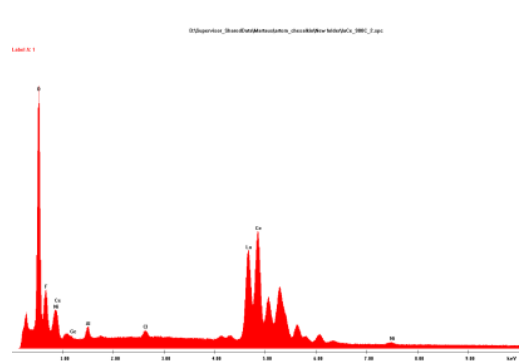

(c)

Figure 11. (LaCe)Nis sample prepared at $900{ }^{\circ} \mathrm{C}$ : (a) sample view at $400 \times$ zoom SEM analysis ; (b) sample view at $4000 \times$ zoom SEM analysis ; (c) SEM spectrum

\subsection{Analysis results of La-Ni bsed alloys prepared from pure powder metals}

\subsubsection{LaNis alloy analysis results}

Tables 9-11 show composition of the LaNi5 sample, prepared at $1500^{\circ} \mathrm{C}$. Figures 12,13 show the SEM analysis images and spectrum of the prepared alloy.

Table 9. Sample LaNi5 prepared at $1500{ }^{\circ} \mathrm{C}$ (La-Ni-O composition).

\begin{tabular}{cccccc}
\hline Element & $\mathbf{W t}, \boldsymbol{\%}$ & $\mathbf{A t}, \boldsymbol{\%}$ & $\mathbf{Z}$ & $\mathbf{A}$ & $\mathbf{F}$ \\
\hline $\mathrm{O}$ & 22,88 & 49,25 & 1,1632 & 0,4157 & 1,0005 \\
$\mathrm{La}$ & 23,59 & 5,85 & 0,8079 & 1,0239 & 1,0102 \\
$\mathrm{Ni}$ & 25,42 & 14,91 & 1,0132 & 0,9729 & 1,0051 \\
other & 28,11 & 29,99 & & & \\
Total & 100,00 & 100,00 & & & \\
\hline
\end{tabular}

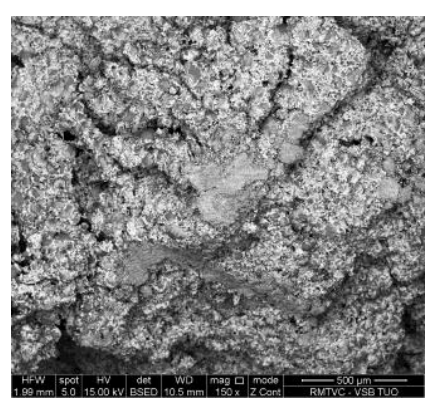

(a)

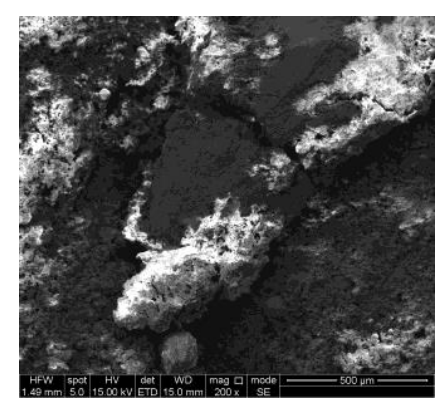

(b)

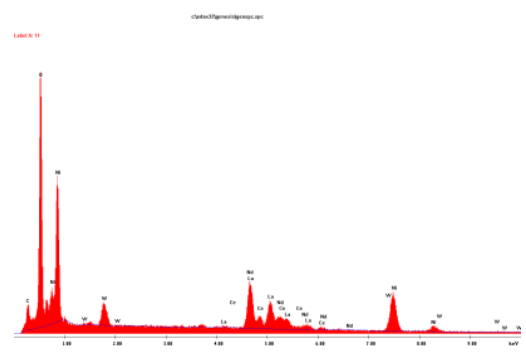

(c)

Figure 12. LaNis sample prepared at $1500^{\circ} \mathrm{C}$ : (a) sample view at 150 x zoom SEM analysis ; (b) sample view at $200 \times$ zoom SEM analysis ; (c) SEM spectrum

Table 10. Sample LaNis prepared at $1500{ }^{\circ} \mathrm{C}$ (La-Ni-O composition, La-phase).

\begin{tabular}{cccccc}
\hline Element & $\mathrm{Wt}, \%$ & $\mathrm{At}, \%$ & $\mathrm{Z}$ & $\mathrm{A}$ & $\mathrm{F}$ \\
\hline
\end{tabular}




\begin{tabular}{cccccc}
$\mathrm{O}$ & 6,60 & 32,62 & 1,3119 & 0,4569 & 1,0004 \\
$\mathrm{La}$ & 74,13 & 42,19 & 0,9227 & 1,0096 & 1,0062 \\
$\mathrm{Ni}$ & 13,41 & 18,05 & 1,1703 & 0,9452 & 1,0007 \\
other & 5,86 & 7,14 & & & \\
Total & 100,00 & 100,00 & & & \\
\hline
\end{tabular}

Table 11. Sample LaNi5 prepared at $1500{ }^{\circ} \mathrm{C}$ (La-Ni-O composition, Ni-phase).

\begin{tabular}{cccccc}
\hline Element & $\mathbf{W t}, \mathbf{\%}$ & $\mathbf{A t}, \mathbf{\%}$ & $\mathbf{Z}$ & $\mathbf{A}$ & $\mathbf{F}$ \\
\hline $\mathrm{O}$ & 8,74 & 23,81 & 1,1702 & 0,4254 & 1,0014 \\
$\mathrm{La}$ & 16,14 & 5,07 & 0,8098 & 1,0239 & 1,0312 \\
$\mathrm{Ni}$ & 50,20 & 37,27 & 1,0117 & 0,9889 & 1,0000 \\
other & 24,92 & 33,85 & & & \\
Total & 100,00 & 100,00 & & & \\
\hline
\end{tabular}

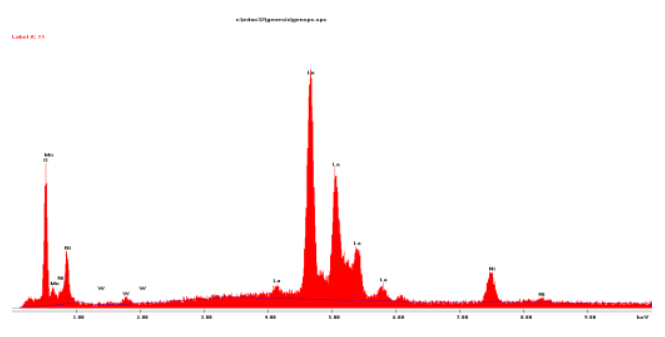

(a)

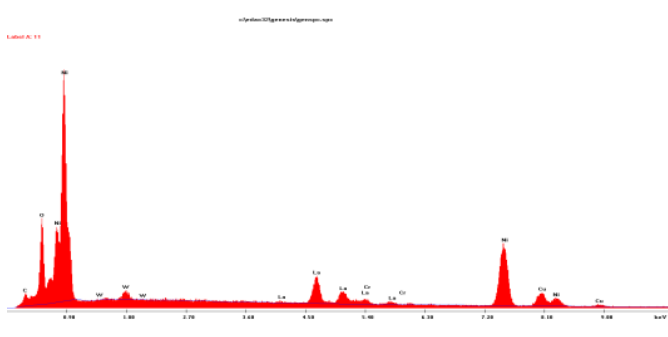

(b)

Figure 13. LaNi5 sample prepared at 1500 0C: (a) SEM spectrum La dominant phase ; (b) SEM spectrum Ni dominant phase

\subsection{2. (LaCe)Nis alloy analysis results}

Tables 12 shows composition of the (LaCe)Nis sample, prepared at $1500^{\circ} \mathrm{C}$. Figures 14 shows the SEM analysis images and spectrum of the prepared alloy.

Table 12. Sample ( $\mathrm{LaCe}) \mathrm{Ni}$ prepared at $1500{ }^{\circ} \mathrm{C}$ (La-Ce-Ni-O composition).

\begin{tabular}{cccccc}
\hline Element & $\mathbf{W t}, \mathbf{\%}$ & $\mathbf{A t}, \mathbf{\%}$ & $\mathbf{Z}$ & $\mathbf{A}$ & $\mathbf{F}$ \\
\hline $\mathrm{O}$ & 17,14 & 47,61 & 1,2319 & 0,4578 & 1,0003 \\
$\mathrm{Ce}$ & 32,53 & 10,32 & 0,8671 & 1,0219 & 1,0025 \\
$\mathrm{La}$ & 34,83 & 11,14 & 0,8619 & 1,0193 & 1,0020 \\
$\mathrm{Ni}$ & 6,88 & 5,21 & 1,0585 & 0,4101 & 1,0000 \\
other & 8,62 & 25,72 & & & \\
Total & 100,00 & 100,00 & & & \\
\hline
\end{tabular}

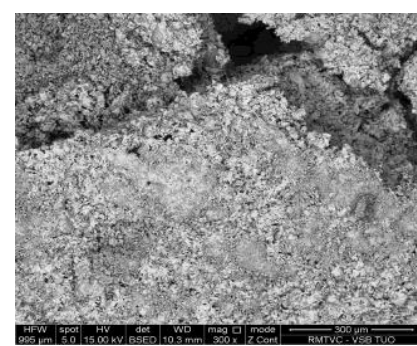

(a)

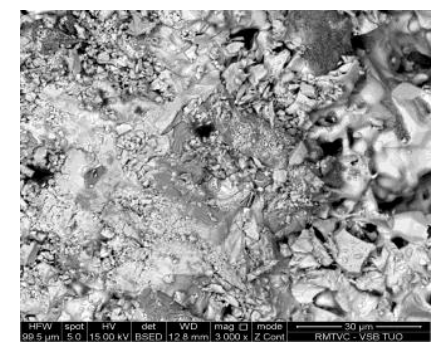

(b)

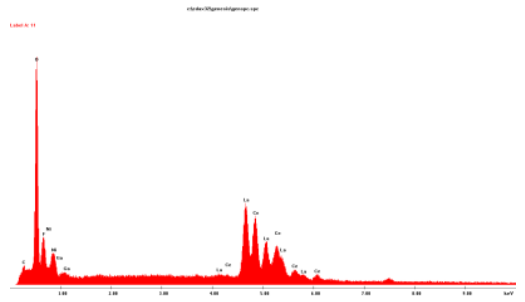

(c) 
Figure 14. (LaCe)Ni5 sample prepared at 1500 0C : (a) sample view at $300 \times$ zoom SEM analysis ; (b) sample view at $3000 \times$ zoom SEM analysis ; (c) SEM spectrum

\subsection{2. (LaMm)Nis alloy SEM and XRD analysis results}

Tables 13 shows composition of the (LaMm)Ni5 sample, prepared at $1500^{\circ} \mathrm{C}$. Figures 15 shows the SEM analysis images and spectrum of the prepared alloy.

Table 13. Sample (LaMm)Nis prepared at $1500{ }^{\circ} \mathrm{C}$ (La-Ce-Fe-Nd-O composition).

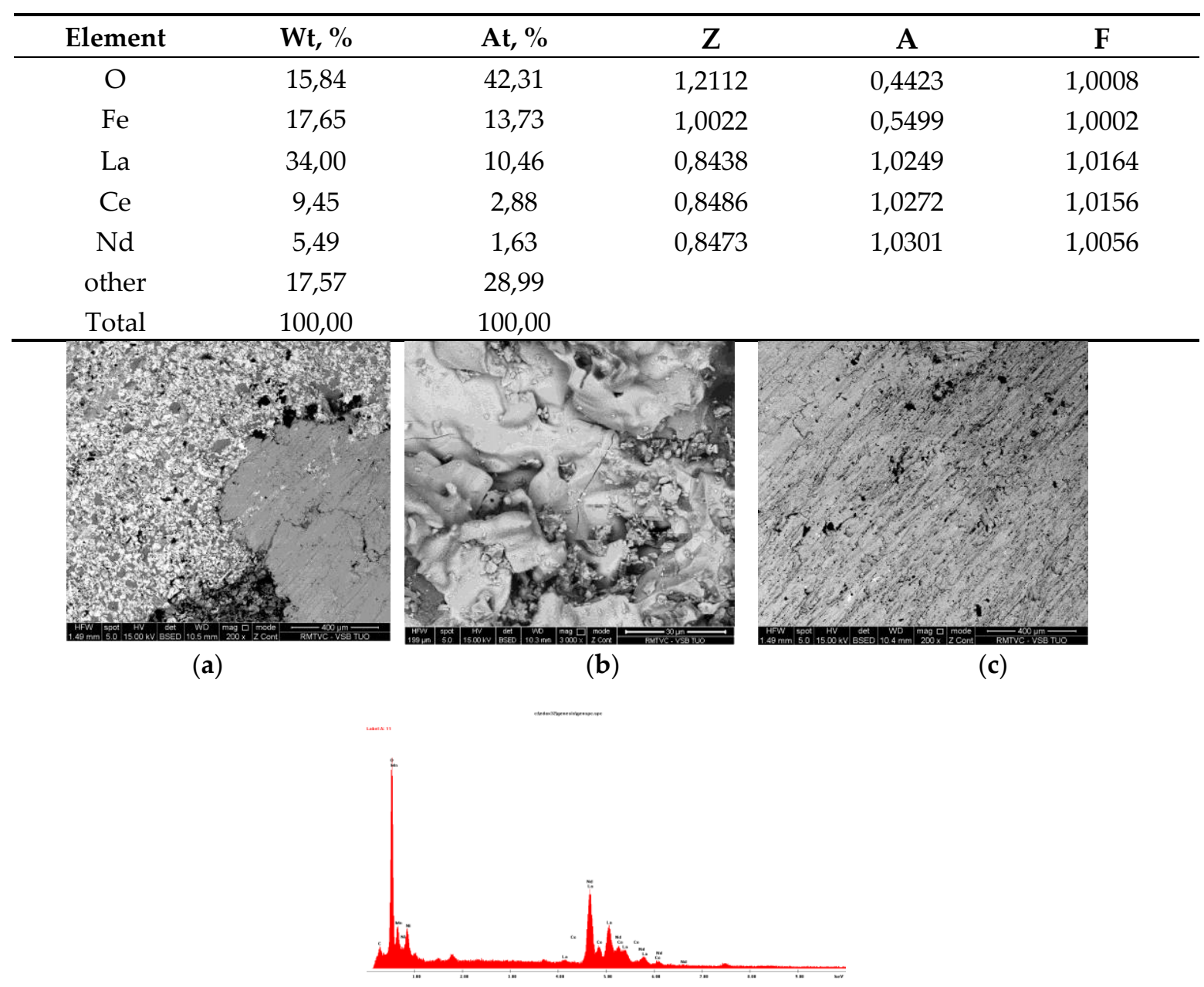

(d)

Figure 15. (LaMm)Ni5 sample prepared at 1500 0C : (a) sample view with phase separation at $200 \mathrm{x}$ zoom SEM analysis ; (b) sample view at 3000 x zoom SEM analysis ; (c) sample view phase $-\mathrm{Ni}$ at 200 $\mathrm{x}$ zoom SEM analysis (d) SEM spectrum.

\section{Discussion}

As can be seen from the results of the qualitative analysis of alloys, most samples were susceptible to oxidation during alloys preparation or subsequent analysis. Nevertheless, the least oxidized samples were confirmed by further analysis of the possibility of hydrogen sorption. In this paper, careful results of hydrogen adsorption on each of the samples will not be described. The following describes the hydrogen desorption parameters in ( $\mathrm{LaCe}) \mathrm{Ni}_{5}$ alloy as on one of the most successful prepared samples.

For discharging of the alloy was used a fuel cell type "Nexa Ballard System" like device with stable and easy to controlled and if necessary, easily variable hydrogen consumption. Constant hydrogen flow is a most important parameter for user or hydrogen consumer (in that case consumer 
is a fuel cell) and thanks to integrated in a fuel cell mass flow meter was possible to control and regulate the discharge flow. In other way free discharge flow without regulation provide very sharp temperature decreasing on a metal hydride side.

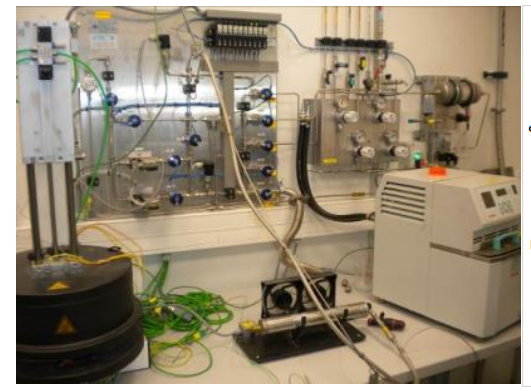

(a)

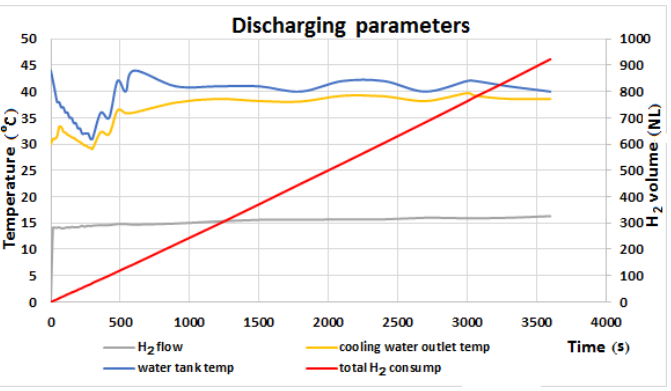

(b)

Figure 16. Hydrogen desorption from the metal hydride storage based on (LaCe)Ni5 alloy (a) basic view of the discharging process $(b)$ discharging parameters

Figure 16 shows the metal hydride discharging process and main discharging parameters. Presence of fuel cell together with the hydrogen storage can be used like the energy storage system and gives possibility to use hydrogen like a source of electrical energy. The connection of fuel cell to the electric load instead of the any grid could provide the effective regulation of discharging flow depends on the fuel cell consumption profile - the regulation of thermal impact during hydrogen desorption cycles. Future works on the synthesis of alloys will be carried out with careful protection of the alloy components and the subsequent products from oxidation. Analysis of alloys not exposed to oxidation will give a complete picture of the possibilities of future La-Ni based alloys modification and the ways of final product cost reducing and hydrogen sorption capacity increasing.

\section{Conclusions}

Results of chemical composition analysis of La-Ni based alloy samples gave useful information about exist problem with alloys synthesis from metal chlorides such as a choosing of optimal timetemperature working parameters of synthesis, which from one side should be enough for creation desired LaNis phase during synthesis, and from other side should be as shorter as possible for energy and time consumption reducing of the synthesis process. Cost of the reagents, which should be used for alloy preparation and respectively cost of the final alloy is the second important issue and the reason why the La-Ni alloys in this job were synthesized from metal chlorides. Next synthesis should be carried out at increased temperature sample holding stage for fully $\mathrm{LaNi}$ phase creation.

Studies of properties, kinetics of different alloys based on metals like $\mathrm{La}, \mathrm{Ce}, \mathrm{Ni}$ or another metals together with polymers, modification of traditional alloys and creation of totally new artificial materials will provide a development of new energy area - hydrogen energetics and hydrogen mobility. Low storage pressure with big amount of stored hydrogen together with a small physical volume of storage vessels provides a big advantage for final user of that system in comparison with classic hydrogen storage methods.

Next researching and modifications of La-Ni based alloys could provide increasing of hydrogen storage capacity and material costs decreasing, that allows to use these storage systems not only in laboratory scale.

Acknowledgments: This work was supported by ENET Centre - Research Centre of Energy Units for Utilization of Non Traditional Energy Sources, Ostrava, CZ., and CET- Centre for Environmental Technology, Ostrava, CZ, supported by the project LO1404: Sustainable development of ENET Centre and project CZ.1.05/2.1:00/19.0389: Development of the research infrastructure of the ENET Centre.

Author Contributions: Artem Chesalkin conceived, designed and performed the experiments, contributed reagents/materials. Petr Modrik provided the TCO and alloys application description. Alexandr Martaus performed the XRD and SEM analysis of prepared alloys. All authors contributed to the writing of the paper. 
Conflicts of Interest: The authors declare no conflict of interest.

\section{References}

1. Rather S., Mehraj-ud-din N., Zacharia R., Hwang S.W., Kim A.R., Nahm K.S. Hydrogen storage of nanostructured $\mathrm{TiO}_{2}$-impregnated carbon Nanotubes, International Journal of Hydrogen Energy 34 (2009) 961-966.

2. Zacharia R., Kim K.Y., Hwang S.W., Nahm K.S. Intrinsic linear scaling of hydrogen storage capacity of carbon Nanotubes with the specific surface area, Catalysis Today 120 (2007) 426-431.

3. Srinivas G., Sankaranarayanan V., Ramaprabhu S. Kinetics of hydrogen absorption in Ho1-xMmxCo2 alloys, Journal of Alloys and Compounds 448 (2008) 159-165.

4. McRae G.A., Coleman C.E., Leitch B.W. The first step for delayed hydride cracking in zirconium alloys, Journal of Nuclear Materials 396 (2010) 130-143.

5. Dong C.F., Liu Z.Y., Li X.G., Cheng Y.F. Effects of hydrogen-charging on the susceptibility of X100 pipeline steel to hydrogen-induced cracking, International Journal of Hydrogen Energy 34 (2009) 9879-9884.

6. Madina V., Azkarate I. Compatibility of materials with hydrogen. Particular case: hydrogen embrittlement of titanium alloys, International Journal of Hydrogen Energy 34 (2009) 5976-5980.

7. J. Huot, Metal Hydrides, in Handbook of Hydrogen Storage, M. Hirscher, Wiley-VCH Verlag GmbH \& Co. KGaA, Weinheim, Germany, 2010.

8. John B. Heywood, Internal Combustion Engine Fundamentals, table D.4 page 915

9. L. Zaluski, A. Zaluska, P. Tessier, J.O. Ström-Olsen, R. Schulz, Catalytic effect of Pd on hydrogen absorption in mechanically alloyed Mg2Ni, LaNi5 and FeTi," Journal of Alloys and Compounds, Volume 217, Issue 2, 1 February 1995, Pages 295-300 (296).

10. B. Sakintuna, F. Lamari-Darkrim, M. Hirscher, Metal hydride materials for solid hydrogen storage: A review, International Journal of Hydrogen Energy, Volume 32, Issue 9, June 2007, Pages 1121-1140 (1128)

11. http://energy.gov/eere/fuelcells/hydrogen-storage Office of Energy Efficiency and Renewable Energy

12. G. Sandrock, A panoramic overview of hydrogen storage alloys from a gas reaction point of view, J. Alloys and Compounds, 293-295 (1999) p. 877-888.

13. Schlapbach, L., Anderson, I.., and Burger, J.P. (1994) Hydrogen in metals, in Electronic and Magnetic Properties of Metals and Ceramics Part II, vol. 3B (ed. K.H. Jurgen Buschow), VCH, Weinheim, p. 271.

14. Libowitz, G.G. (1991) presented at the Hydrogen Storage Materials, Batteries, and Electrochemistry, Phoenix, Arizona, Electrochemical Society Proceedings (eds D.A. Corrigan and S. Srinivasan), 92-5, 3.

15. Flanagan, T.B. (1977) presented at the Hydrides for Energy Storage, Geilo, Norway, Pergamon (eds A.F. Andresen and A.J. Maeland).

16. Flanagan, T.B. and Oates, W.A. (1988) Thermodynamics of Intermetallic Compound-Hydrogen Systems, in Hydrogen in Intermetallic Compounds I (ed. L. Schlapbach), Springer Verlag, Berlin, p. 49.

17. Griessen, R. and Riesterer, T. (1988) Heat of formation models, in Hydrogen in Intermetallic Compounds I (ed. L. Schlapbach), Springer-Verlag, Berlin, pp. 219.

18. Yamaguchi, M. and Akiba, E. (1994) Ternary hydrides, in Electronic and Magnetic Properties of Metals and Ceramics Part II, vol. 3 (ed. K.H. Jurgen Buschow), VCH, Weinheim, p. 333.

19. 44 Fukai, Y. and Okuma, N. (1993) Jpn. J.Appl. Phys., 32, L1256.

20. G.Giresan, S.R. Sankaranarayanan, L.J. Berchman, Investigation on the thermodynamic analysis, preparation and characterization of $\mathrm{LaNi}_{5}$ - hydrogen storage alloy by magnesiothermic reduction diffusion process, Tamilnadu, India.

21. S. Kamasaki, Y. Misaki, T.Kanayama, M.Yamada, Surface modification of hydrogen storage alloy LaNis by milling with Al and Co powders, Hyomen Gijutsu Kyokai, Tokyo, (1989)

22. A. Ursua, I. San Martin, E.L. Barrios, P. Sanchis, Stand-alone operation of an alkaline water electrolyser fed by wind and photovoltaic systems. International Journal of Hydrogen Energy, 2013, vol. 38, no. 35, pp. 14952-14967.

23. F. Barbir, PEM electrolysis for production of hydrogen from renewable energy sources. Solar Energy, 2005, vol. 78, no. 5, pp. 661-669.

24. A. Yilanci, I. Dinger, H.K. Ozturk, A review on solar-hydrogen/fuel cell hybrid energy systems for stationary applications. Progress in Energy and Combustion Science, 2009, vol. 35, no. 3, pp. 231-244.

25. D. Minarik, B. Horak, P. Moldrik, Z. Slanina, An experimental study of laboratory hybrid power system with the hydrogen technologies. AEEE Advances in Electrical and Electronic Engineering, 2014, vol. 12, no. 5, pp. 518-528. 
14 of 14

26. http://www.actaspa.com/products/aes250/,http://www.actaspa.com/wpcontent/uploads/2013/08/AES500-1000.pdf "ACTA AES500-1000 technical data sheet.

27. http://www.lac.cz/en/furnaces-and-dryers/vp-high-temperature-furnace "LAC VP20/17 technical parameters". 